\title{
La información cultural en los diccionarios de ELE (o De cómo ponerle puertas al campo) ${ }^{1}$
}

\author{
Concepción Maldonado González \\ Ediciones SM / Universidad Complutense de Madrid \\ concha.maldonado@grupo-sm.com \\ mariaconcepcionmaldonado@pdi.ucm.es
}

Resumen: Este texto pretende transmitir el enorme valor social de la lexicografía. Creemos en el servicio social que como lexicógrafos podemos (y debemos) prestar al mundo. Y creemos que son muchas las posibilidades que tenemos delante si somos capaces de despertar del letargo de varios siglos de tradición, entendida como mera repetición de inercias de trabajo. Queremos abrir una línea de reflexión sobre la enseñanza de español como segunda lengua, con el hilo conductor de la relación entre léxico y cultura, y la plasmación que de esa relación se hace y se puede hacer en corpus y en diccionarios. Si asumimos que todos somos aprendientes de otras lenguas (o de otras variedades de la lengua propia), y si vivimos esta diversidad como una riqueza; si tomamos conciencia de que todos (como profesores, como editores, y como estudiantes) somos preparadores de materiales, y si recogemos en ellos esa diversidad como una riqueza; y si encaramos con ilusión la tarea de ser todos mediadores entre las distintas culturas, y reflejamos esa diversidad de culturas como una riqueza, entonces, y solo entonces, estaremos ayudando a mostrar la diversidad de culturas con normalidad en nuestro quehacer diario en el mundo ELE.

Palabras clave: Diccionario, español lengua extranjera o segunda lengua, información cultural, culturema.

1. Una versión más breve de este texto fue presentada como ponencia plenaria el 7 de septiembre de 2017, en el XXVII Congreso Internacional de ASELE, celebrado en Tarragona, en la Universitat Rovira i Virgili, del 6 al 8 de septiembre de 2017. 
Abstract: This text aims to communicate the tremendous social value of lexicography. We firmly believe in the social service that we, as lexicographers, can and should provide to society, and we see many possibilities before us, provided we can awaken from the centuries-long slumber where tradition merely repeats work done by force of habit. When we accept that we are all learners of other languages (or variations of our own language) and experience this diversity as an asset, when we become aware that all of us (whether teachers, publishers or students) prepare materials and when we incorporate diversity as an asset within these, and when we enthusiastically approach the task of mediating between different cultures and reflect this diversity of cultures as an asset, only then will we be helping to showcase cultural diversity as the norm in our day-to-day work in the world of Spanish as a Foreign Language.

Key words: Dictionary, Spanish as a foreign language or second language, cultural information, culturema.

Recibido el 28/09/2017

Aceptado el 04/11/2017 


\section{Introducción}

El planteamiento de este texto es muy sencillo: nuestra intención no es sino ser capaces de transmitir el enorme valor social de la lexicografía. Creemos en el servicio social que como lexicógrafos podemos (y debemos) prestar al mundo. $\mathrm{Y}$ creemos que son muchas las posibilidades de trabajo que tenemos delante si somos capaces de despertar del letargo de varios siglos de tradición, entendida como mera repetición de inercias de trabajo. Nuestro trabajo es una reflexión sobre un tema de enorme actualidad en la didáctica de segundas lenguas. No es este un trabajo empírico, con resultados concretos; nuestra intención es plantear cuestiones que lleven a la reflexión y a la investigación. Traemos, por tanto, más preguntas que respuestas. Nuestras palabras intentan pellizcar nuestra conciencia dormida, para empezar a mirar con confianza al futuro y dejar de repetir un pasado que, a fuerza de ser tantas veces repetido, no conseguimos nunca dejar atrás.

Y ya tenemos aquí un primer ejemplo de esas repeticiones en las que no reparamos... Acabamos de dibujar el pasado, detrás; el futuro, delante, en una concepción lineal del tiempo que lleva ineludiblemente a concebir este como una flecha que solo nos permite ir hacia delante, nunca hacia atrás. Traigamos a colación la película La llegada (Arrival)², esa adaptación al cine de uno de los relatos de Ted Chiang titulado La bistoria de tu vida (Chiang, 2005); y recordemos la relación que existe entre la lengua de los alienígenas heptápodos y su concepción del tiempo... O bien recordemos el conocido estudio que la Revista Chilena de Antropología recoge sobre la concepción del tiempo en la cultura aimara, una concepción en la que la metáfora dominante es el círculo o la rueda que gira en un movimiento, además, contrario a la dirección de las manecillas del reloj (Grebe, 1990: 63). O, por último, pensemos en cómo otras lenguas amerindias perciben el futuro detrás de los hablantes: no lo ven porque no lo conocen; la vida es un avanzar de espaldas, hacia atrás, hacia lo desconocido que está por venir, sin dejar de ver lo ya vivido, el pasado, que es lo que queda siempre delante de nosotros.

Y preguntaremos si, a partir de estos datos, alguien afirmaría que estos pueblos amerindios, por fuerza, son incapaces de manejar todas esas herramientas informáticas de planificación, seguimiento y control de un proyecto mediante las cuales se visualiza el desarrollo del mismo en una secuencia organizada de flechas temporales que van de izquierda a derecha, superpuestas y encadenadas...

No queremos llegar a conclusiones simplistas. Pero tampoco queremos dejar de plantearnos las premisas que han de conducirnos a algún tipo de conclusión.

2. Heisserer, E. (productor) y Villeneuve, D. (director) (2016). Arrival (La llegada) [cinta cinematográfica]. Italia: Paramount Pictures. 
Por todo lo visto, en este artículo trataremos la relación entre los diccionarios y la realidad en ellos reflejada (apdo. 1), y abriremos una línea de reflexión sobre la relación entre léxico y cultura en la didáctica de segundas lenguas (apdo. 2) y sobre su plasmación en los diccionarios (apdo. 3), para concluir destacando la necesidad de trabajar conjuntamente docentes y editores de materiales, ante el papel de mediadores que nos asigna la diversidad de culturas (un papel de mediadores al que no queremos ni debemos renunciar) (apdo. 4).

\section{Los diccionarios: puertas y ventanas.++ ¿abiertas o cerradas al mundo?}

Intentaremos explicar ahora la visión que hemos querido transmitir con el subtítulo de este artículo.

\section{1 «De cómo ponerle puertas al campo»}

Poner puertas al campo no es intentar algo estúpido o inútil, o intentar hacer algo imposible; poner puertas al campo es «dar a entender la imposibilidad de poner límites a lo que no los admite»³.

Nos atrevemos, por tanto, a afirmar que poner puertas al campo sería pretender que los profesores de español para extranjeros nos centremos solo en la enseñanza de la gramática, o solo en la enseñanza del léxico, o solo en la enseñanza de una buena pronunciación.

Poner puertas al campo sería intentar establecer fronteras como muros entre los conceptos de formación y educación.

Poner puertas al campo sería comportarnos como el individuo parapetado tras el mostrador en la viñeta"

\section{DLE (2014).}

3. Esta viñeta fue ya utilizada por nosotros en la mesa redonda Pasado, presente y futuro de los diccionarios para el aprendizaje de español, en el XXIV Congreso Internacional de ASELE, celebrado en la Universidad de Jaén,del 18 al 21 de septiembre de 2013. 


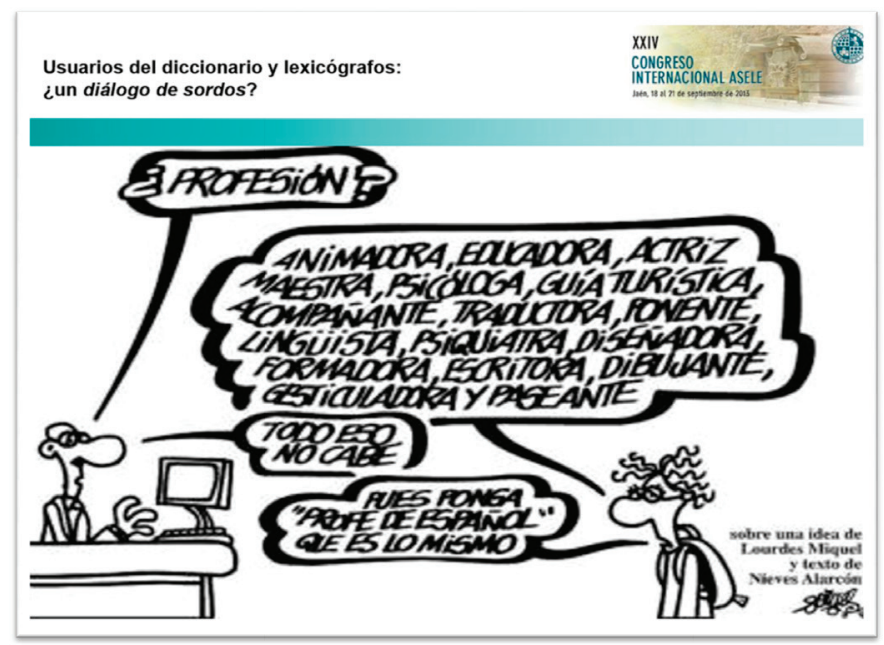

Hubo otros subtítulos antes (también basados en metáforas visuales). Los analizaremos a continuación, ya que, aunque todos ellos fueron al final descartados, todos tenían un mismo objetivo: pellizcar nuestra conciencia lexicográfica ${ }^{5}$.

\section{2 «Los diccionarios, ventanas abiertas al mundo»}

Las ventanas por las que nos asomamos a mirar, y nuestra posición en ellas, determinan lo que vamos a ver (no es lo mismo un ventanuco que un ventanal; ni una claraboya que un ojo de buey; ni una vidriera que un tragaluz...).

Según Millás (2009), «la palabra es en cierto modo un órgano de visión [...]. Un mundo sin palabras no nos volvería mudos sino ciegos [...]. Cada vez que conquistamos una nueva palabra, la realidad se estira, el horizonte se amplía, nuestra capacidad intelectual se multiplica».

Por ello, solo quien ha viajado entre las páginas de antiguos diccionarios se ha dado cuenta experiencialmente de que leer diccionarios de épocas pasadas es asomarse al mundo desde una óptica propia de entonces. Los cronistas de Indias contaron en el siglo xvi cómo era el Nuevo Mundo, y lo hicieron desde parámetros comparativos con su mundo de siempre, con unas descripciones de las nuevas realidades marcadas por su propio punto de vista vital, geográfico y temporal. Como señala Forgas $(2002)^{6}$ :

5. Por cierto, que los pellizcos de monja, tan conocidos y nombrados por los niños de nuestra generación, no se recogen ya en el diccionario combinatorio Práctico; en el corpus de prensa panhispánica del que se extrajeron los datos para dicho diccionario, los pellizcos eran o bien de dinero, o bien de sal, azúcar, pimienta y pan.

6. Colón, C. (1983). Textos y documentos completos. Edición de Consuelo Varela. Madrid: Alianza. Citado por Aínsa, F. (1992: 152). 
El mismo Colón escribe en su diario del 7 y 8 de diciembre que en el mundo que ha descubierto hay "lenguados como los de Castilla, paxaritos y ruiseñores como los de Castilla, árboles y yerbas como las de Castilla y vegas las más hermosas del mundo y cuasi semejantes a las tierras de Castilla”, aunque más tarde cambiará de parecer y escribirá que los árboles "son diversos de los nuestros, con flores y con su fruto, cada una a su manera" y las aves son "de muchas maneras diversas de las de España". La realidad americana puede ser comparable o incomparable, pero el punto de referencia sigue siendo el mismo.

Pero es que en pleno siglo $\mathrm{xx}$, y esta es una anécdota bien conocida en el ámbito de la lexicografía, un joven Gabriel García Márquez se sorprendía del color que el entonces DRAE decía que tenían los limones (en América, son verdes). De hecho, como hemos señalado en otras ocasiones (Maldonado, 1997), siempre nos sorprendía que en algunos diccionarios escolares se dijera que el besugo es un pescado de exquisito sabor, pese a que a nosotros, de pequeños, ese ojo que nos miraba desde la fuente de horno nos produjera más de una pesadilla. De la misma manera, a muchos españoles nos produce extrañeza el llamado caviar mexicano (los escamoles), esas larvas de la hormiga güijera, igual de caras que las huevas de esturión. Y solo si hemos viajado a México y nos hemos sentado en torno a una mesa en la que se sirven chapulines (saltamontes), podamos quizá entender lo que algunos extranjeros sienten ante un plato de quisquillas...

Y reflexionar sobre esto no es solo reflexionar sobre la enseñanza de la lengua y la cultura españolas; es reflexionar sobre la variadísima realidad panhispánica (gastronómica, en este caso) contada con palabras del español.

\section{3 «El diccionarioः a menudo, una puerta cerrada al mundo»}

Solo quien lee la prensa atento a este fenómeno percibe, mes a mes, la crispación y la rabia que a menudo aqueja a los hablantes de una lengua cuando constatan la lentitud y la resistencia de algunos repertorios lexicográficos para dar entrada a las palabras frescas que nacieron recién de una sociedad viva y en marcha. Sirva de ejemplo el hecho de que el diccionario académico no incluyera el matrimonio homosexual hasta siete años después de su legalización en España. O, por citar solo algunos de los casos posibles, que el repertorio académico aún no haya recogido el bimi (injerto de triguero y brócoli) o la quinoa, por mucho que ambos ingredientes figuren en el menú del restaurante más cercano a la sede del Instituto de Lexicografía de la RAE... Y no es que vayamos a afirmar, como se hace a menudo desde el desconocimiento, que esas palabras no existen (en un símil de Javier López Facal [2011a], ¿a algún botánico que paseando por el campo 
encuentra una hierba desconocida y que no figura en su libro de botánica se le ocurre decir que esa hierba no existe?).

Es recurso fácil (y muy agradecido) rastrear en cualquier diccionario el sinfín de palabras que no se recogen: aun hoy, el color camel, juegos como el frisbi, o deportes como el bobsleigh siguen fuera del repertorio académico. Pero lo que casi nos interesa más analizar aquí es el proceso inverso: aquel en el que los hablantes queremos que la realidad cambie y pensamos que para ello es suficiente con cambiar el lenguaje que la nombra, con cerrar la puerta del diccionario a la realidad y dejar así fuera del mismo las palabras que nombran dichas realidades. Y, si no, repasemos las campañas que, a través de Change.org proponen (cada vez con más frecuencia) la eliminación de determinadas palabras del diccionario académico. Y citemos aquí solo algunos ejemplos más o menos anecdóticos, como el de la Asociación en Defensa del Borrico de Córdoba, que pide, edición tras edición, que se elimine la segunda acepción de burro; o como la más reciente, del gremio de los panaderos, al pedir en junio de este mismo año que se elimine la expresión pan con pan, comida de tontos, por más que dicha expresión no figure en ese diccionario académico del que piden que se excluya...

\section{4 «Los diccionarios, el mundo y las puertas giratorias»}

Las puertas giratorias (ese invento del estadounidense Van Kannel, patentado en 1888, y que permite un elevado flujo de personas entrando y saliendo de un edificio) hoy son una forma coloquial de designar el hecho de que un alto cargo público, una vez finalizado este, empiece a trabajar en una empresa privada. En japonés, en cambio, se conoce este fenómeno como amakudari (literalmente 'descenso del paraíso/cielo'), en referencia a la mitología japonesa, donde se produce el descenso de los dioses sintoístas a la tierra. ¿Habremos de deducir, entonces, que los japoneses son un pueblo con la mirada puesta en los dioses para los que el paraíso es el Estado y el acceso a la empresa privada su expulsión del mismo?7

Pues bien, ese imaginar el diccionario como una puerta giratoria se encuentra en la base de la concepción, tan tradicionalmente arraigada, del diccionario como el libro que contiene todas las palabras de una lengua. Gabriel García Márquez, en su prólogo al diccionario Clave, afirma que él tenía cinco años cuando su abuelo el coronel le llevó a conocer animales de un circo de paso en Aracataca y confundió un dromedario con un camello. Aquella tarde el abuelo volvió abatido a la casa, y continúa García Márquez:

7. Parece claro que la respuesta ha de ser la misma que daríamos a la pregunta de si los occidentales somos capaces de inventar cualquier dispositivo con tal de no tener que ceder el paso a las mujeres (el bulo que ha acompañado desde sus orígenes a la explicación de este invento de las puertas giratorias...). 
Me llevó a su sobria oficina con un escritorio de cortina, un ventilador y un librero con un solo libro enorme. Lo consultó con una atención infantil, asimiló las informaciones y comparó los dibujos, y entonces supo él y supe yo para siempre la diferencia entre un dromedario y un camello. Al final me puso el mamotreto en el regazo y me dijo:

-Este libro no solo lo sabe todo, sino que es el único que nunca se equivoca.

Era el diccionario de la lengua, sabe Dios cuál y de cuándo, muy viejo y ya a punto de desencuadernarse. Tenía en el lomo un Atlas colosal, en cuyos hombros se asentaba la bóveda del universo. "Esto quiere decir -dijo mi abuelo- que los diccionarios tienen que sostener el mundo". Yo no sabía ni leer ni escribir, pero podía imaginarme cuánta razón tenía el coronel si eran casi dos mil páginas grandes, abigarradas y con dibujos preciosos [... ]. Fue como asomarme al mundo entero por primera vez.

- ¿Cuántas palabras habrá? -pregunté.

-Todas -dijo el abuelo.» ${ }^{8}$

Las palabras y la realidad nombrada por ellas, entrelazadas ambas por una relación biunívoca: cada término, nombrando una realidad; cada realidad, nombrada por un término.

Es posible que haya mucho que opinar sobre las instituciones oficiales y su responsabilidad en la conversión de esas puertas giratorias en tornos (o torniquetes) para controlar el acceso peatonal a un recinto ${ }^{9}$. Pero baste ya de pasear por el ámbito de los subtítulos que pudieron haber sido y no fueron, y volvamos al subtítulo elegido: De cómo ponerle puertas al campo...

Fue esa visualización de un campo inabarcable (los grupos humanos, la sociedad, la cultura, la cosmovisión, la identidad), y la experiencia de trabajo de la necesidad de recoger todo eso en un diccionario finito dirigido a usuarios muy concretos, lo que nos hizo decantarnos por esta expresión que, de hecho, ni en francés ni en inglés tiene equivalente (y empezamos así a introducir ya el concepto de culturema).

\section{Una reflexión y muchos retos}

Por deformación profesional (responsable de un equipo de trabajo en una empresa privada), antes de abordar la ejecución de cualquier proyecto habremos de tenerlo definido con respuestas claras y concisas a estas siete preguntas: qué

8. Maldonado, C. (dir.) (2012a: IX).

9. Esto era lo que antes indicábamos (apdo. 1.1), cuando nos referíamos a los diccionarios como puertas cerradas a las nuevas corrientes de aire que ventilan el mundo. 
queremos hacer, por qué, para qué, para quién, cómo, en cuánto tiempo y con qué recursos.

Hagamos este mismo proceso de reflexión para garantizar que el mensaje que intentamos transmitir llega a buen puerto.

\subsection{Objetivos de esta exposición}

Queremos abrir una línea de reflexión sobre la enseñanza de español como segunda lengua, con el hilo conductor de la relación entre léxico y cultura, y la plasmación que de esa relación se hace y se puede hacer en corpus y en diccionarios.

¿Tenemos claro que un culturema de España (salga el sol por Antequera ${ }^{10}$ no es un culturema del español? ¿Somos conscientes de que las ideas de bombero son solo 'ideas locas' en el español de España? Y, si bien todos los hispanohablantes hemos sentido alguna vez dolores musculares tras un esfuerzo físico intenso y no habitual, ¿sabíamos que solo en España existe un término (agujetas) para nombrarlo?

Existe una realidad panhispánica: hablamos español de forma nativa desde la Patagonia hasta el estado de Washington; en Guinea Ecuatorial y en México; en Filipinas y en Andorra. Y existe también un panhispanismo oficial promovido por la Asociación de Academias de la Lengua Española (ASALE) desde los años noventa del siglo pasado. Ese panhispanismo se define como una política lingüística cuyo fin es promover la unidad del español a partir de la descripción de todas las variedades geográficas de nuestra lengua sin priorizar ninguna de ellas sobre las demás. Por eso el DRAE ya no es el DRAE, sino el DLE (cambio nominal consolidado por ASALE a partir de la vigésima tercera edición de 2014). Por eso dicho DLE incluye ya con normalidad la definición de términos como durazno, rosetas o pororo ${ }^{11}$ sin definirlos en relación al melocotón y a las palomitas de maíz, respectivamente.

No pensemos que ya está todo hecho, sin embargo. Por desgracia, aún son muchísimos los términos que siguen definiéndose con una remisión (en negrita o no) al término por el que conocemos esa realidad en el español de España, igual que Colón, hace más de quinientos años, describía la realidad americana por comparación con la de Castilla: chabacano es, en México, albaricoque; chile sigue siendo pimiento en Costa Rica, El Salvador, Guatemala, Honduras, México y Nicaragua; el colectivo es autobús en Argentina, Bolivia, Ecuador, Paraguay y

10. En el español actual, esta expresión se usa para expresar determinación al hacer algo a pesar de las consecuencias. Su origen se remonta a la época de los Reyes Católicos. Al estar Antequera situada a poniente de Granada, la expresión tiene un marcado tono de ironía por la imposibilidad de lo que expresa.

11. Las crispetas colombianas o el pochoclo argentino aún no se recogen en la última edición del diccionario académico. 
Perú; la bencina es gasolina (como lo es la nafta en Argentina, Paraguay y Uruguay). Y las cometas que los niños españoles vuelan en la playa son la referencia lexicográfica que los niños argentinos deben consultar cuando buscan el significado de barrilete; o los niños chilenos, cubanos y puertorriqueños cuando buscan el significado de volantín; o los venezolanos cuando buscan el significado del papagayo; o los mexicanos, hondureños y venezolanos cuando quieren saber qué es un papalote.

El llamado español neutro es la otra gran política lingüística del español en el mundo, una política promovida por los grandes medios de comunicación hispanos, con el fin de obtener la máxima rentabilidad económica en la producción empresarial de noticias escritas o habladas, telenovelas, doblaje de películas, etc. Un español neutro del que se imparten cursos en Buenos Aires (Guevara: 2013); un español neutro que algunos prefieren llamar español internacional (Bravo: 2008), y que un conocedor de las variedades americanas del español como Humberto López Morales (2006) describe como un resultado más de la globalización. De hecho, resulta evidente que las tecnologías y las nuevas formas de interacción social que estas han posibilitado favorecen una homogeneización mucho mayor que en el pasado (entendiendo por pasado los años anteriores a los inicios de este siglo XXI.+*).

¿Cómo conviven estas dos políticas lingüísticas? ¿Se complementan? ¿Se contraponen? ¿Conviven en paralelo? Creemos que el gran reto que tiene la producción lexicográfica académica para el siglo xxi no es ni su digitalización ni su recoger el ingente caudal léxico del mundo hispanohablante en una obra acumulativa que sume entradas de artículos lexicográficos con el fin de recoger el léxico propio de cada variedad geográfica del español, sino la descripción de todas esas variedades redactadas en el geolecto propio de cada una de ellas (solo así serán pertinentes para los usuarios y no les resultarán ni ajenas ni forzadas), y el establecimiento léxico y semántico de las relaciones entre dichas variedades, unas relaciones que la concepción digital de la lexicografía permite establecer con facilidad y de forma intuitiva para el consultor de los repertorios lexicográficos.

Creemos que mientras el panhispanismo oficial no renuncie a su carácter acumulativo y cuantitativo, no conseguirá reconciliarse de nuevo con esos usuarios que, desde hace años, y por diversos motivos, no se ven representados en esa descripción geocentrista del español.

Si todos asumimos con naturalidad ver en nuestras calles y plazas cómo las terrazas están llenas de extranjeros que hablan a sus dispositivos móviles para que sean estos los que, a partir de la fotografía de un texto escrito en la carta del local, o a partir de un dictado oral en su lengua nativa, traduzcan al español la co- 
manda para el camarero, ¿por qué no soñar con que dentro de no mucho tiempo podamos hablar a nuestros dispositivos para decirles que queremos un bocadillo de jamón y sean ellos los que nos enseñen que en Uruguay eso es un sándwich de pernil? ¿Por qué no aspirar a que si pedimos un café solo en Colombia, nuestro celular lo traduzca por un tinto, ya que un café (solo, sin el adjetivo solo al lado) es allí siempre un café con leche...?

Con estos ejemplos solo estamos refiriéndonos a realidades compartidas, pero nombradas de forma diferente. No entramos ya en ese otro día a día en el que el extranjero que estudia español en España preferirá entender conceptos como salmorejo cordobés, ternasco segoviano, bollo maimón salmantino, las gachas manchegas o las mantecadas de Astorga con una carta con fotografías y con el listado de los ingredientes antes que mediante la consulta a un diccionario (por muy en línea que esté dicho diccionario y por muy gratuita que sea su consulta), del mismo modo que un extranjero que estudie español en Chile querrá antes saber qué es la caluga, el dulce de alcayota o un quequito a la hora de hacer o tomar las once...

\subsection{Aportación de la lexicografía a la enseñanza de español como segunda lengua}

Un diccionario no solo describe la lengua, sino que también, y sobre todo a través de una lengua, transmite una cultura, como ya hace treinta años, en 1987, señaló Alain Rey, responsable editorial de Le Robert, en su artículo Le dictionnaire culturel. Los profesores de ELE, por tanto, no debemos limitarnos a explicar el significado de las unidades léxicas, sino que debemos enseñar a nuestros alumnos a rastrear buscando en ellas los valores culturales implícitos que constituyen la identidad de esa comunidad de hablantes. Insistimos: no estamos hablando de nombrar realidades locales como el gazpacho o la paella. Nos referimos más bien a ese léxico marcado diatópicamente que nos remite a distintas realidades sociales. Pensemos, por ejemplo, en ese moreno Agromán (¿hoy deberíamos decir moreno Ferrovial Agromán?), que en nuestra generación describía el moreno típico del peón de albañil, un bronceado del tronco muy pronunciado y oscuro, pero solo en las zonas que la camiseta deja sin cubrir mientras se trabaja a pleno sol, día tras día, en la obra. Era un moreno despreciado por ser el moreno típico de la clase obrera, tan distinto del moreno bien distribuido por todo el cuerpo y propio de los baños de sol que las clases sociales más adineradas se podían permitir en las playas españolas. Era un moreno que en francés se traduce como moreno de Marcel, sin que sepamos quién era ese tal Marcel aunque intuyamos que un parisino del Distrito Séptimo no era... 
Con estas reflexiones, estamos intentando trascender la tópica y típica dificultad de enseñar a un extranjero cómo se traducen, por ejemplo, los adjetivos valorativos del tipo de cutre, hortera, cursi, macarra o pijo, tan difíciles de definir. Estamos hablando de abrir los ojos y la mente (de abrir las puertas y ventanas lexicográficas) para no reírnos de la lentitud implícita en el ahorita mismo mexicano y aprender a reírnos también con esa duda que con tanta claridad expresa nuestro españolísimo adverbio seguramente...

\subsection{De la teoría lexicográfica a la didáctica de segundas lenguas}

Los lexicógrafos generalistas y los especialistas en español como lengua extranjera podemos avanzar de la mano. Nadie sabe más que todos juntos. De hecho, la invención del orden alfabético, «sin duda el más arbitrario de los órdenes imaginados por el ser humano, y, sin embargo, el más universalmente aceptado (no se sabe de nadie que haya intentado subvertirlo)» (Millás, 2009); ese orden alfabético es lo que ha definido la lexicografía tradicional. El ahorro de espacio y el orden alfabético han sido los dioses tiranos del olimpo lexicográfico hasta principios del siglo Xxi. Y ahora, en menos de cuatro lustros, ese orden alfabético carece de sentido en el entorno digital: un entorno en el que la falta de espacio no es criterio que defina nada. La sobreinformación es, si acaso, el único problema relacionado de forma directa con la capacidad ilimitada de almacenar la información.

El orden alfabético es la servidumbre que la lexicografía ha pagado al soporte papel desde sus orígenes. Hoy estamos en un cambio de paradigma (Kuhn, 1962), no en un mero cambio de soporte. Los lexicógrafos hemos pasado de ser meros hacedores de diccionarios a ser organizadores de información lingüística orientados a proporcionar dicha información a las máquinas que hacen de intermediarias entre los usuarios y nosotros. La información, por digital, es cada vez más abundante, y el conocimiento y el uso del español cada vez es más global. Como enseñantes de ELE la decisión consciente que debemos tomar es definir qué variedad del español queremos enseñar: ¿la local y espontánea en nosotros (esa que nos lleva a los españoles a coger por igual el autobús y el teléfono aunque estemos en México) o la neutra e internacional que nos hace forzarnos a tomar el autobús y agarrar el teléfono para que nuestro mensaje resulte no marcado en cualquier ámbito en el que se hable español? 


\subsection{Destinatarios de estas reflexiones}

Cualquier profesor de español para extranjeros sabe de estas cuestiones bastante más que un lexicógrafo generalista, porque son los profesores en activo los que están en el aula y los que a diario se enfrentan a las necesidades de sus alumnos a la hora de desentrañar el significado oculto de las palabras... ¿Cómo explican los docentes a sus alumnos que, en español, los imprevistos crecen o brotan como setas; las mercancías se venden como churros o como rosquillas si los clientes acuden como moscas; que las verdades son grandes como puños; que nos ponemos alegres como unas castañuelas, o que cantamos como los ángeles...?

¿Qué raíces culturales o tradicionales se esgrimen en clase para explicar que, en español, estamos fuertes como robles (no como castaños) o que sudamos como pollos (aunque los pollos no tengan glándulas sudoríparas)? ¿Por qué estamos sordos como una tapia y somos fuertes como una roca, o duros como una piedra (que no al revés)? ¿O por qué pensamos que las ostras se aburren, y que las cabras están locas (de hecho, ¿qué tienen en común una chota, una chiva, un cencerro o una regadera para que elementos tan dispares sean el segundo término de una comparación con el significado de 'loco'?

Con los ejemplos anteriores, no estamos refiriéndonos a expresiones con clara base cultural por designar realidades propias de los ámbitos temáticos más propicios a reflejar la ideología de un grupo social (por ejemplo, el mundo agrario que reflejan expresiones como medir por el mismo rasero, ser más bruto que un arado o ser fuerte como un toro), sino a esas llamadas comparaciones prototípicas o elativas que antes mencionaba y que están presentes en cualquier lengua natural como fruto de una herencia cultural que para el español ha estudiado Satorre (2015), en una labor de rastreo que ha dejado de manifiesto cómo más claro que el agua, oscuro como boca de lobo o sano como una manzana ya estaban presentes en Covarubias en 1611.

Y todas estas preguntas, todos estos retos, queremos plantearlos desde la inquietud del cambio de paradigma cultural que estamos viviendo; desde la incertidumbre de lo que el futuro nos deparará; desde las preguntas y los interrogantes, más que desde las respuestas y las certezas. Y, por supuesto, desde el convencimiento de la riqueza que encierra siempre la puesta en común de experiencias reales de trabajo, con la esperanza de que, al menos en el terreno académico, podamos aprender en cabeza ajena. 


\section{Diccionarios y cultura}

Los diccionarios describen el léxico. Y el léxico rezuma cultura, por mucho que nunca sea reflejo directo de la misma. De hecho, Galisson (1991: 119) acuñó el término lexicultura para dar cuenta de la relación innegable entre las competencias léxica y cultural, al confirmar «la existencia de significados culturales presentes en unidades léxicas culturalmente compartidas por los miembros de una comunidad, los cuales aparecen en ocasiones desapercibidos, o bien suponen un problema de incomprensión o alta dificultad para el hablante no nativo» (López y Morales, 2013: 1). En otras palabras, son matices o referentes ocultos en el acervo lingüístico de una comunidad dada; y en ese carácter oculto es donde radica su dificultad, como bien queda de manifiesto en todas esas situaciones inesperadas que los docentes vivimos en las aulas ante las preguntas y observaciones de los alumnos que estudian en situación de inmersión.

No es el momento para definir aquí el concepto de cultura ${ }^{12}$. Y justificaremos esta decisión con tan solo tres ejemplos que explican por qué no es este el lugar para profundizar en ese concepto:

a. En primer lugar, recordemos cómo en 2008 saltaba a los medios de comunicación la discusión que en las comisiones académicas se abordaba esos días en la propia Real Academia Española sobre la conveniencia o no de incluir nuevas acepciones en el artículo lexicográfico de la palabra cultura para que cupieran también expresiones como la cultura del vino, la cultura del esfuerzo y la icultura? de la droga ${ }^{13}$.

b. Un segundo ejemplo que pone de manifiesto la amplia gama de conceptos que en el habla cotidiana se encierran bajo el término cultura sería el hecho de que el Ministerio de Educación, Cultura y Deporte haya colgado en su web unos Tesauros del patrimonio cultural de España en los que encontraremos un diccionario de objetos asociados a ritos, cultos y creencias; otro, de cerámica; otro, de numismática; otro, de mobiliario, etc. Y parece evidente que no es esto (una taxonomía elaborada con el objetivo de normalizar la terminología museística) lo que busca el estudiante de ELE cuando consulta en la web información sobre el patrimonio cultural español.

12. Cualquier hablante de nuestra generación encontraría normal el fácil recurso de parodiar aquí la Rima XXI de Bécquer: ¿Qué es cultura? ¿Y tú me lo preguntas? Nos tememos, sin embargo, que en las nuevas generaciones no sigue muy vigente hoy ese conocimiento compartido...

13. El 21 de diciembre de 2008 aparecía en la edición impresa de El País este reportaje de Jesús Ruiz Mantilla y Tereixa Constenla: «Cultura de diccionario. La Real Academia Española redefine el concepto y valora nuevas acepciones. Las referidas a costumbres generan las mayores discusiones entre los académicos». [https://elpais. com/diario/2008/12/21/cultura/1229814001_850215.html (última consulta: 19 de junio de 2017)]. 
c. Por último, recordaremos cómo en 2005, en cambio, Prado Aragonés analizaba diez términos tópicos de la cultura española y su distinto tratamiento en diferentes diccionarios ELE; y cómo es un hecho cierto que un estudiante de ELE agradece más la explicación de esos diez términos (bandolero, castizo, flamenco, siesta, procesión, fallas, sanfermines, paella, gazpacho y sangría) que los ingentes listados de la web antes citada.

No pondremos puertas al campo de la cultura por las mismas razones por las que Fernández Montoro no lo hace en su excelente artículo de 2014: porque lo que nos ocupa no es ilustrar qué es la cultura, sino enmarcar los contenidos culturales dentro del componente léxico. Sí citaremos aquí sus palabras, con referencia a la metáfora del iceberg de Weaver:

Weaver ejemplifica que cuando nos acercamos a otra cultura solo el 5 o el $10 \%$ (las tradiciones, la comida, las costumbres, el vestido, el arte, etc.) es perceptible frente al 90 o $95 \%$ que conforma la parte que permanece oculta, la parte menos reconocible a primera vista (la visión del mundo, los valores, las creencias, la forma de sentir o de reaccionar). (Fernández Montoro, 2014: 16)

Por ello, nos contentaremos con poner aquí de manifiesto cómo unidades léxicas transparentes para un nativo resultan del todo opacas para un extranjero (culturemas). Y pondremos el foco en la necesidad de que ni como lexicógrafos ni como profesores ni como editores nos conformemos con describir, enseñar o explicar en cantidad las unidades léxicas, sino que nos centremos en explicar su uso en los contextos más adecuados a partir de los valores socioculturales que nos transmiten:

No es suficiente con aprender o enseñar gran cantidad de unidades léxicas, sino, especialmente, saber cómo funcionan en el discurso, en qué contexto son más adecuadas o qué asociaciones socioculturales evocan o transmiten, con lo cual se enriquece su uso y se facilita la entrada a la realidad cultural meta. (Fernández Montoro, 2014: 15).

\subsection{Diccionarios y culturemas}

No profundizaremos tampoco (recuerden que nuestra intención no era traer respuestas sino preguntas) en el concepto de culturema, esos fenómenos propios y específicos de una cultura y que quedan de manifiesto sobre todo cuando dicha cultura se compara con otra en la que dicho culturema no es pertinente (los culturemas se dan siempre en el marco de dos culturas concretas). De hecho, y como señala Luque Nadal con mucha claridad (2009: 96): «Podríamos decir que una 
palabra $\mathrm{X}$ funciona como culturema entre las lenguas $\mathrm{A}$ y $\mathrm{B}$, pero no necesariamente entre las lenguas $\mathrm{A}$ y $\mathrm{C} »$.

Los culturemas no constituyen un grupo cerrado de elementos. Con el tiempo, algunos pierden validez y otros van incorporándose a la lengua. Veamos algunos ejemplos:

En las generaciones actuales, temas clásicos como la caja de Pandora son mucho menos conocidos que Cupido, las musas o los cantos de sirena; tres temas estos que entre las nuevas generaciones resultan menos cercanos que la mirada asesina del basilisco o que el resurgir constante del ave fénix a partir de sus cenizas (aunque la reaparición de estos conceptos haya venido de la mano no de un profesor de Clásicas sino de la lectura voraz de las aventuras de un aprendiz de mago llamado Harry Potter).

Nuestros hijos seguramente conocen la procedencia bíblica de David y de Goliat, o del maná caído en el desierto, o del diluvio universal y el arca de Noé, pero quizá no conocen la historia del plato de lentejas por el que Esaú vendió la primogenitura a Jacob (Génesis 25,29-34); y casi es seguro que desconocen el origen bíblico de expresiones como las uvas de la ira (Apocalipsis 14,19-20) o carros de fuego (2 Reyes 6,15-17) ${ }^{14}$.

Un hispanoamericano quizá no conozca el valor de la historia de España encerrado en expresiones como una defensa numantina, ${ }^{15}$ tener la manga ancha, ${ }^{16}$ los reinos de taifas; ${ }^{17}$ pero es que, por las mismas razones, un español quizá no captará la equivalencia del chupacabras mexicano con el ogro de los cuentos españoles...

Los niños de hoy no imitan el sonido de la corneta del séptimo de caballería al mando del general Custer como ejemplo de todo lo que acude a salvarnos en el último segundo, pero sí que imitan el habla entrecortada de Davy Jones en la versión que de él nos presenta Piratas del Caribe ${ }^{18}$; y huyen en sus juegos de pillapilla

14. Para un estudio sobre las referencias bíblicas en distintas lenguas, véase Luque Nadal (2010).

15. Defensa numantina es aquella defensa que se lleva hasta el límite pese a los ataques de un adversario más poderoso. La expresión tiene su origen en la resistencia que la ciudad celtíbera de Numancia presentó en el siglo II a. C. ante el asedio romano (los numantinos prefirieron el suicidio colectivo antes que rendirse).

16. Esta expresión significa 'ser tolerante ante las faltas propias o ajenas', y alude a la permisividad que tradicionalmente se atribuía a los dominicos en la confesión (sus hábitos tenían las mangas anchas), frente al carácter más estricto y exigente que se atribuía a los jesuitas.

17. Las taifas eran cada uno de los pequeños reinos independientes en que se dividió la España musulmana al disolverse el califato cordobés.

18. Personaje secundario en la serie cinematográfica Piratas del Caribe (Pirates of the Caribbean), producida por Jerry Bruckheimer, que hasta ahora cuenta con cinco partes. 
al grito de Corred, insensatos $^{19}$; y desean suerte a sus amigos diciéndoles ;Que la fuerza te acompañe?

Vemos, pues, que los culturemas pueden ser específicos de un país (jSantiago $y$ cierra, España! $)^{21}$ o pueden ser compatibles con zonas culturales de una misma tradición (en cualquier territorio del occidente cristiano, se hable la lengua que se hable, se entenderán expresiones como ser más falso que Judas ${ }^{22}$ o llorar como una Magdalena $a^{23}$ o ser más viejo que Matusalén ${ }^{24}$ ), porque «los culturemas son unidades de información con las que nuestro cerebro cuenta para entender cómo es el mundo» (Luque Nadal, 2009: 117). Y coincidimos con el Grupo de Investigación de Lingüística Tipológica y Experimental (GILTE) de la Universidad de Granada (que trabaja desde 1997 en temas relacionados con el léxico y la cultura, y que en la actualidad está elaborando un Diccionario interlingüistico e intercultural en más de diez lenguas), en señalar que la contribución que el estudio de los culturemas supone en la enseñanza de segundas lenguas es propia del nivel avanzado. De hecho, recordemos que el estudio de los culturemas empezó no en el campo de la enseñanza de segundas lenguas, sino en el campo de la traductología, en los años ochenta del siglo pasado, como un elemento muy didáctico y válido para explicar la relación entre traducción y cultura ${ }^{25}$.

Bien es verdad que no todas las expresiones lingüísticas con un valor cultural, por muy específica que sea esa cultura, son culturemas. De los cuatro criterios que Luque Nadal (2009: 105-107) ofrece para diferenciar los culturemas de los fraseologismos, solo destacaremos, por claro y didáctico, el hecho de que la interpretación de los fraseologismos no depende del contexto extralingüístico (algo que, en cambio, sí ocurre con los culturemas). ¿ $\mathrm{O}$ es que alguien que no haya visto

19. Frase de Gandalf en La comunidad del anillo, primera parte de la trilogía de fantasía épica El señor de los anillos (J. R. R. Tolkien, 1954-55: The Lord of the Rings).

20. Esta frase (en inglés, May the Force be with you) es una frase utilizada por los personajes de Star Wars, saga cinematográfica de ciencia ficción creada por George Lucas.

21. Grito de guerra utilizado por las tropas cristianas desde la Reconquista en su lucha contra las tropas musulmanas. Santiago es el patrón de España; cerrar en la jerga militar significa 'atacar, combatir'; y el vocablo España hace referencia al destinatario de la frase: las tropas españolas.

22. Por alusión a Judas Iscariote, el apóstol que traicionó a Jesús a cambio de dinero (Mt 26,14; Mc 14,10; Lc 22,3; Jn 13,26).

23. Por alusión a María de Magdala, discípula de Jesús que aparece en varios pasajes del Nuevo Testamento (los cuatro evangelios la citan como la primera testigo de la resurrección: Mt 28,1-10; Mc 16,1-11; Lc 24,1-11; Jn 20,1-18).

24. Según la Biblia (Gn 5,21-27) vivió 969 años.

25. Sobre esta tradición de estudios, véase un estado de la cuestión en Petrescu (2008: 140-148). 
ciertos anuncios televisivos entenderá eso de hacer la prueba del algodón ${ }^{26}$, o el dicho de Aceptamos pulpo como animal de compañía?

\subsection{Diccionarios e ideología}

¿Nos metemos en otro jardin? Precisaremos, de hecho, que, cuando éramos pequeños, nuestros abuelos nos decían que no nos metiéramos en charcos ni en sembrados... Y aún hoy creemos que resultan más transparentes para un extranjero expresiones como meterse en un laberinto o meterse en un berenjenal ${ }^{28}$.

No inventamos la pólvora, ni la rueda (ni siquiera, el agua tibia), si alertamos aquí sobre la imposibilidad de elaborar un diccionario con definiciones neutras. Y, aun así, instamos imperiosamente a la necesidad de intentarlo cada vez: « Aunque no es posible lograr del todo la neutralidad, es, eso sí, imprescindible, tratar de acercarse a ella» (Forgas, 2006: 2). Muchos antes que nosotros han descrito esta cuestión (Pascual, 1991; Forgas, 2001, 2006). En los ámbitos educativos, es común la ¿broma? de asumir que educar es a menudo sinónimo de manipular... Y en las facultades de Ciencias de la Información es habitual discutir sobre si los verbos tergiversar y manipular son intercambiables en el discurso. Paremos un momento en este punto.

El término tergiversar tiene su origen en el latín. El verbo tergiversor, tergiversari, tergiversatum está compuesto por el sustantivo tergum, tergi (cuyo significado es 'espalda, dorso') y por el verbo verto, vertere, verti, versum (que significa 'hacer girar' o 'volver'). Los romanos usaban este verbo con valor despectivo para las personas cobardes que no eran capaces de enfrentar sus propias acciones y que requerían del uso de la mentira o del reacomodo de las palabras para que las cosas se interpretaran a su conveniencia. El concepto etimológico de esta palabra es, pues, 'volver la espalda a los acontecimientos' o 'de espaldas al sentido o dirección'.

El significado hoy en español es 'realizar una interpretación errada o falaz, no importa si de manera intencional o no, de determinados acontecimientos, dichos o palabras'. Es decir, la tergiversación puede ser consciente o inconsciente, pero es. Podemos mentir a propósito o sin querer, pero mentimos cuando alteramos

26. En el año 1995 se hizo famoso un anuncio de televisión en el que un ama de casa creía que su cocina estaba limpia hasta que un mayordomo aparecía por allí y, pasando un algodón por los azulejos, le mostraba cómo el algodón quedaba negro por la suciedad. El mayordomo, a continuación, limpiaba a fondo la cocina con el producto anunciado, y lo dejaba todo reluciente y limpio, de modo que, al volver a pasar un algodón sobre los azulejos, el algodón seguía blanco e impoluto.

27. En 1996, en el anuncio de un juego de mesa en el que los participantes tienen que nombrar determinados ejemplos de un concepto dado, el dueño del juego se enfadaba porque los demás le decían que el pulpo no valía como animal de compañía. Al levantarse enfadado de la mesa y llevarse el juego con él, todos los demás terminaban cediendo y daban por válida su respuesta con tal de poder seguir jugando.

28. Solo quien ha cultivado berenjenas sabe por experiencia propia cómo los pinchos de esta hortaliza destrozan las manos al trabajarla en la huerta. 
las palabras dichas por otra persona. Creemos que no hay error mayor en un periodista; no hay error mayor en un emisario.

La manipulación es siempre consciente y al servicio de unos fines particulares; la tergiversación, en cambio, puede ser accidental y por descuido, pero las consecuencias son igualmente graves.

El arma más eficaz contra la tergiversación es la intención consciente de ser fiel a la verdad; es la conciencia de que la realidad queda siempre filtrada por las palabras de quien la describe. Siempre. Sin excepción.

El día a día del lenguaje consiste en contar con palabras la realidad que vivimos. Y por mucha apariencia de fidelidad que esa narración tenga, siempre es el hablante el que, por ejemplo, está reproduciendo las palabras de otro, o sus propias palabras; y lo hace en una situación comunicativa distinta de la original $y$, por tanto, en una situación comunicativa que no es aquella en la que el enunciado surgió (Maldonado, 1991). Veamos un sencillo ejemplo. Nunca podremos adivinar qué dijo exactamente Juan, cuáles fueron sus palabras exactas, a partir de ninguna de estas declaraciones:

- Juan me dijo que me amaba.

- Juan me dijo que me quería.

- Juan se me declaró.

- Juan manifestó su amor por mí.

- Juan se vino arriba y quiso emular a Romeo...

Pues bien, si pasamos de las declaraciones de amor a tareas más prosaicas como la redacción de un diccionario, es importante recalcar de nuevo que esa ¿manipulación o tergiversación? ideológica no impregna solo la selección de los lemas. ¿¿Deben entrar vulgarismos? Nuestra experiencia es que, por ejemplo, no pueden incluirse en los repertorios del inglés si vas de la mano de una editorial anglosajona, ya que su tradición lexicográfica no admite el registro de lemas vulgares por considerarlos ofensivos en exceso; en repertorios del castellano, en cambio, su presencia no suele resultar ofensiva.

De hecho, afecta también al tratamiento de dichos lemas. Por ejemplo, en 1993, en nuestro primer diccionario escolar (Intermedio), ofrecíamos ya el género femenino en profesiones tradicionalmente desempeñadas por varones, fueran estas especialidades técnicas (neurocirujana) o trabajos menos específicos (autobusera); y viceversa: aparecían hombres trabajando como secretarios y mujeres médicas que pedían el instrumental quirúrgico a los enfermeros, por mucho que 
hasta fechas muy recientes ${ }^{29}$ la convocatoria anual del MIR siguiera hablando de plazas de enfermeras aunque los varones pudieran optar a ellas.

Pensemos ahora en el orden de las acepciones: ¿por criterio histórico-etimológico o por criterio de uso? La respuesta parece clara en el caso de diccionarios ELE: por uso: la azafata (y el azafato) de los aviones (en este caso, aeromoza y aeromozo para muchos países americanos) y de los congresos deben preceder a la antigua camarera de la reina. Pero no olvidemos que ese criterio se cruza con la tradición lexicográfica de agrupar las acepciones por identidad categorial (y eso supone que verde, como color (adj.inv./s.m.) aparece definido en un diccionario de uso (Clave, 2012) en la acepción 12, por detrás de las diez acepciones en que verde es adj.inv., y por detrás también de la única acepción en que es adj.inv./s. com. (la acepción asociada a 'ecologista').

Pensemos también en la redacción de definiciones y ejemplos. Ya en 1989 redactábamos definiciones con fórmulas en las que conscientemente queríamos evitar que, por ejemplo, afeminado fuera definido con un simple 'que parece de mujer' (DLE, 2014) y matizábamos que algo es afeminado cuando tiene «las características consideradas tradicionalmente ${ }^{30}$ propias de las mujeres» (Intermedio, 1993). Del mismo modo, se procuraba, conscientemente, que los hiperónimos fueran igual de respetuosos con todas las doctrinas filosóficas o religiosas, por muy heterodoxas que las mismas pudieran resultar a los redactores. $\mathrm{O}$, por citar algún otro ejemplo, se incluían términos coloquiales despectivos como polaco o charnego, pero en ambos se incluían ejemplos muy parecidos:

- Mi familia es catalana y mis padres me enseñaron desde pequeña a no llamar charnegos a mis compañeros de clase que eran hijos de inmigrantes.

- Mis padres son andaluces y me enseñaron desde pequeña a no llamar 'polacos' a mis compañeros de clase que eran catalanes.

Pensemos, por último, en las notas gramaticales y de uso que orientan, entre otros, sobre el carácter despectivo o discriminatorio de algunas palabras. ¿Es vulgar o coloquial cabrearse? ¿Papá y mamá son términos solo propios del habla infantil? ¿Pararse es solo quedarse quieto? ¿Es despectivo el coloquialismo español perder aceite?

Recordemos: los lexicógrafos somos el filtro que, con palabras, retrata el mundo en el que vivimos. Y los retratos pueden ser realistas, abstractos, impresionistas o caricaturescos. El estilo (léxico, que no pictórico) por el que optemos

29. En 2008, en el Real Decreto 183/2008, de 8 de febrero, por el que se determinan y clasifican las especialidades en Ciencias de la Salud y se desarrollan determinados aspectos del sistema de formación sanitaria especializada (MIR), se habla todavía de la exigencia de un título universitario oficial de enfermera.

30. El subrayado es nuestro. 
determinará la interpretación que se lleven de la realidad pintada por nosotros todos los visitantes que se acerquen a nuestra exposición de palabras...

\subsection{Diccionarios e identidad nacional}

La Academia Mexicana de la Lengua, en la persona de Concepción Company, presentó en sociedad el Diccionario de mexicanismos en 2011 como un ejemplo de la identidad mexicana.

Creíamos que este tópico estaba ya superado en el siglo Xxi. Pero vemos con asombro que, aunque los especialistas así lo entendamos, cuando queremos reforzar nuestra identidad como pueblo o cuando queremos acercar el sentido de nuestro trabajo a la sociedad, seguimos apelando al sentido lingüístico de los hermanos Humboldt ${ }^{31}$.

Company basó su presentación en hacer evidente la estrecha relación entre lengua, cultura y sociedad, y escogió como ejemplos para demostrarlo algunas pautas de lexicalización al entender que estas «indican dónde los hablantes mexicanos ponen el énfasis», porque «las lenguas codifican o formalizan mejor aquello que es cultural y cognitivamente importante en una determinada comunidad».

Company citaba cuatro rasgos:

+ La reinterpretación de la pluralidad como un intensificador valorativo (y señalaba la cantidad de sustantivos en plural que se lexicalizan como interjecciones; ¡mocos!, ¡boinas!, ¡sobres!, ¡cuernos!, ¡sopas!, ¡changos!, ¡charros!, etc.).

- La multitud de denominaciones para el órgano sexual, especialmente el masculino.

- La multitud de formas para nombrar la muerte.

- La codificación de la transgresión a las normas: mordida, mocharse, arreglo... (a este respecto, Company llega a afirmar que «el hecho de hacer de la transgresión una práctica común amerita una reflexión sobre la sociedad que somos y que queremos ser»).

31. Wilhelm von Humboldt (1767-1835) y Alexander von Humboldt (1769-1859). 


\section{Algunas observaciones desde la propia experiencia}

\subsection{Como docente}

No es nuestra intención sentar cátedra sobre cuestiones relacionadas con la docencia en el aula de español como segunda lengua (ni sobre ninguna otra cuestión, la verdad). Solo querríamos recordar aquí cómo «facilitar la competencia intercultural» es una de las ocho competencias descritas por el Instituto Cervantes en el documento Las competencias clave del profesorado de lenguas segundas $y$ extranjeras (2012: 19-20). Y esta competencia se desglosa en cuatro:

\section{Implicarse en el desarrollo de la propia competencia intercultural}

El profesor toma conciencia de su propia identidad cultural y, por ejemplo, se hace consciente de la cantidad de expresiones taurinas que manejamos en España. Déjenme, pues, que salte al ruedo y me arrime, y que me ponga el mundo por montera toreando este morlaco con una larga cambiada que me deja una salida airosa sin necesidad de que ustedes entren todavía a matar por mis ejemplos...

\section{Adaptarse a las culturas del entorno}

El profesor debe hacerse consciente, por ejemplo, de los valores gestuales y de la sistematización cultural de la comunicación no verbal: solo cuando lo hemos vivido aprendemos la importancia en la cultura china de entregar y recibir un regalo con las dos manos extendidas o hacerlo solo con una; o entendemos el gesto con el que los franceses dicen de alguien que ha bebido alcohol en exceso; o enseñamos en clase que en España tosemos aposta cuando queremos advertir con disimulo a nuestro interlocutor sobre la presencia de alguien cuya presencia el interlocutor no contempla...

En este campo, el del estudio de los movimientos gestuales como herramienta de comunicación, tenemos un ejemplo claro de la necesidad de despertarnos en lexicografía. Gaviño dirige hace años un proyecto ambicioso e innovador, consistente en crear en la web un repositorio, abierto a todos, en el que se recogen fotográficamente los gestos más habituales en España. El orden alfabético no rige para las fotos, ni siquiera para el rótulo lingüístico con que se etiqueta cada gesto. Pues bien, ¿ por qué no ir más allá? ¿Por qué no ordenar desde la semántica? ¿Por qué no atrevernos a soñar con otro tipo de entrada al léxico? En su descripción de cómo sería un diccionario de definiciones mínimas, Bosque y Mairal (2012a, 2012b) se atrevieron a soñar cómo, igual que desde rural todos llegamos al concepto de campo, se podía crear una ordenación del léxico que permitiese desde campo llegar a rural. Del mismo modo, :por qué no llegar a los gestos desde los 
valores semánticos por ellos expresados, de modo que la onomasiología sea la que nos lleve desde el concepto de cantidad al concepto de mucho o poco, y de ahí, a los gestos distintos con que expresamos mucha gente o much a comida?

De hecho, la puerta de entrada a un signo gestual resulta evidente que puede ser la parte del cuerpo con que realizamos dicho gesto (así es como está ordenada ahora la información en la web), pero eso nos ayudará solo a descodificar; si queremos que nuestros alumnos se atrevan a codificar gestos propios de nuestra lengua y de nuestra cultura, creemos que el camino ha de ser del significado al gesto, y no al revés.

\section{Fomentar el diálogo intercultural}

El profesor fomenta el diálogo y media para evitar malentendidos culturales: en España a un cumplido se suele responder con un seco Gracias solo si hay mucha confianza entre los hablantes; si no, la persona piropeada suele restar importancia a lo alabado, aportando alguna característica que lo desmerece (si es un jersey el que provoca el halago, Resultó muy barato..., o Está ya muy viejecito..., o no estamos seguros de que nos siente tan bien...).

\section{Promover que el alumno desarrolle su competencia intercultural}

El profesor tiene que enseñar a contrastar que los españoles engañamos como a un chino, pero que los franceses dicen que alguien habla inglés como una vaca española; y que, como vimos antes, no sabemos quién era Marcel, pero es el que da nombre en Francia al moreno Agromán de España. Y que, en paralelo a estos ejemplos, encontramos otras expresiones que, sin poderse traducir tampoco desde la literalidad, se entienden sin problema si imaginamos la realidad nombrada con ellas: por ejemplo, cuando alguien se maquilla en exceso, en francés se dice que va pintado como un camión robado... 


\subsection{Como editora o preparadora de materiales (aunque estos sean lexicográficos $+_{++}$)}

En la siguiente figura ${ }^{32}$ vemos datos reales y actuales a partir de los cuales nos gustaría plantear algunas preguntas que nos lleven a reflexión:

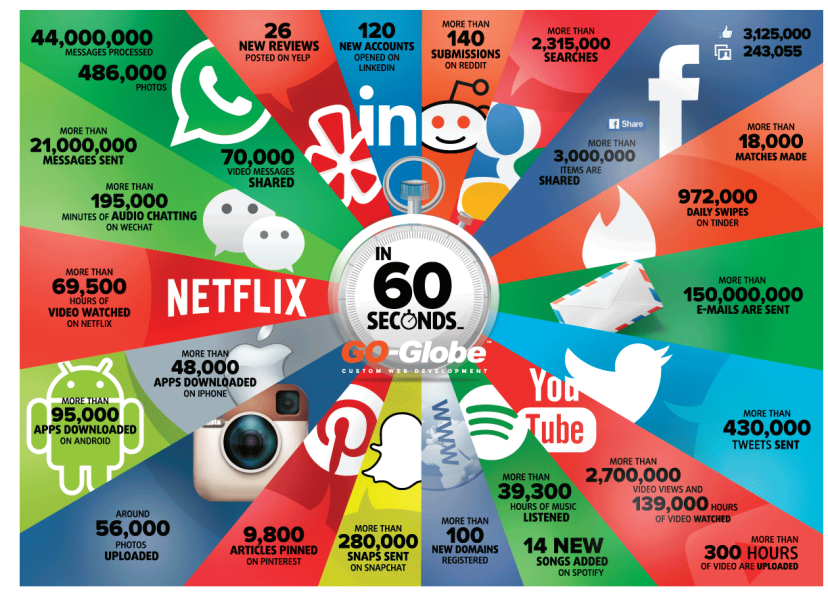

¿Deben los diccionarios elaborarse a partir de corpus o basta el uso de la web para obtener los datos lingüísticos?

¿Debe variar la labor del lexicógrafo desde el momento en que el destinatario final de nuestro trabajo ahora no son los usuarios tanto como las máquinas que proveen de información a los mismos?

¿Cambian los criterios de calidad que debemos aplicar en la valoración de un diccionario desde el momento en que el soporte papel ya parece totalmente eliminado en la concepción actual de este tipo de obras?

¿Deberíamos introducir en el tradicional debate sobre la conveniencia o no de la lexicografía bilingüe o monolingüe en el aprendizaje de segundas lenguas un tercer elemento discordante y relacionado con las más modernas teorías de la traducción?

Traducir significa desplazar espiritualmente la obra de una cultura específca hasta otra cultura de acogida, fenómeno que supone una especie de traslado de elementos lingüísticos, culturales, sociales y antropológicos. (Petrescu, 2008: 142)

Traducimos, pues, los profesores de ELE. Traducimos los editores. Traducimos los que estudiamos lenguas extranjeras. Traducimos los que usamos mate-

32. Fuente: GO-Globe [https://www.go-globe.com/blog.php (última consulta: 19 de junio de 2017)]. 
riales didácticos de enseñanza de lenguas. Pero, sobre todo, insistimos de nuevo en la importancia de saber elegir no ya entre el simple préstamo (integración de una palabra de otra lengua, tal cual hacemos con el sushi, el kebab o el micuit, o como hacen otras lenguas con nuestra guerrilla o nuestra fiesta o nuestra siesta) o las paráfrasis con las que explicamos un elemento cultural del texto original con otro propio de la cultura del texto meta (los gallinazos limeños de las novelas de Vargas Llosa han sido a veces torpemente traducidos por «una especie de gallinas grandes que vuelan»). Insistimos en la importancia de que advirtamos a nuestros alumnos que las fórmulas mexicanas de saludo Quiubo o Ándale, son eso, fórmulas mexicanas; o que los juegos gramaticales como la transitivización del verbo en la pregunta ¿Se murió o la murieron? son juegos de los que no sabemos si, como afirma Petrescu (2008: 168), con el tiempo y en un mundo global, pasarán de ser algo exótico a ser algo compartido entre las culturas, con lo cual perderán la calidad de culturemas.

En 2004, y a raíz de un análisis de materiales didácticos que hizo la editora Pilar García sobre la imagen inadecuada que a veces se transmite en cuanto al tratamiento de la cultura (estereotipos, etnocentrismo, enfoques exclusivos del otro), esta especialista en la edición de materiales didácticos de español para extranjeros expresaba su deseo de que los materiales del futuro siguieran diez líneas de actuación que posibiliten que alumnos y docentes adquiramos una serie de habilidades que nos permitan un diálogo intercultural real en el aula y fuera de la misma. En esta misma línea de trabajo, damos la bienvenida a tantos y tantos trabajos doctorales (o de fin de máster o de fin de grado) que en los últimos años analizan desde la introspección y el estudio crítico de la propia experiencia todos esos malentendidos culturales que se producen entre dos culturas y dos lenguas que conviven ${ }^{33}$.

\section{Conclusiones}

Poner puertas al campo es intentar poner límites a lo que no los tiene.

Hacer dudar es aplicar el método socrático a la indagación o a la búsqueda de nuevas ideas y conceptos o a nuevos enfoques subyacentes en la información. La escalada de preguntas parece no tener límite. Lo que sí ha quedado claro es que la lista de preguntas aquí planteadas no ha ido, en absoluto, acompañada del mismo número de respuestas...

Todos somos aprendientes de otras lenguas (o de otras variedades de la lengua propia). Vivamos esta diversidad como una riqueza.

33. Basten como ejemplo López y Morales (2013) o Luan (2017). 
Todos, como profesores, como editores, como lexicógrafos y como estudiantes, somos preparadores de materiales. Los diccionarios y los materiales didácticos de enseñanza de segundas lenguas son instrumentos muy adecuados para recoger la realidad cultural de una lengua. Recojamos en ellos esa diversidad como una riqueza.

Todos somos mediadores entre las distintas culturas (como todos somos mediadores entre la cultura familiar que hemos mamado, por ejemplo, y la cultura heredada que encontramos en la pareja cuando iniciamos una vida en común). Recojamos esa diversidad de culturas como una riqueza, y ayudemos a mostrarlas con normalidad en nuestro quehacer diario en el mundo ELE.

Ponerle puertas al campo es pensar en la utopía, en ese no-lugar al que todos soñamos llegar aun sabiendo que no existe; pongámonos en camino; persigamos nuestros sueños de hacer de este mundo un mundo mejor usando mejor esas palabras que nos definen y con las que intentamos definir el mundo que nos rodea.

\section{Referencias bibliográficas}

Academia Mexicana de la Lengua (2010). Diccionario de mexicanismos. México DF: Academia Mexicana de la Lengua y Siglo XXI Editores.

Ainsa, F. (1992). «Invención del "otro" y desconstrucción de la realidad en el discurso fundacional de la alteridad americana». II Simposio de Filología Iberoamericana. Zaragoza. Pórtico: 138-159.

Asale (2014). Diccionario de la lengua española, 23. a ed. Madrid: Espasa.

Bécquer, G. A. (2006). Rimas. Madrid: Cátedra.

Bosque, I. (dir.) (2004). REDES. Diccionario combinatorio del español contemporáneo. Madrid: SM.

Bosque, I. (dir.) (2006). Diccionario combinatorio práctico del español contemporáneo. Madrid: SM.

Bosque, I. y Mairal, R. (2012a). «Definiciones Mínimas». En: F. Rodríguez (ed.). Estudios de lingüística española. Homenaje a Manuel Seco. Universidad de Alicante: 123-136.

Bosque, I. y Mairal, R. (2012b). «Hacia una organización conceptual del definiens. Capas nocionales del adverbio arriba». En: D. Corbella, J. Dorta, A. Fajardo Aguirre, L. Izquierdo, J. Medina López y A. Nelsi (eds.). Lexicografía bispánica del siglo XXI: nuevos proyectos y perspectivas. Homenaje al profesor Cristóbal Corrales Zumbado. Madrid. Arco Libros: 125-150.

Bourdin, G. L. (2014). «En los tiempos de ñaupa: el cuerpo y la deixis temporal en lenguas originarias de Sudamérica». Peninsula, 9, $1[<\mathrm{http}$ ://www.scielo. 
org.mx/scielo.php?script=sci_arttext\&pid=S1870-57662014000100002> (última consulta: 19 de junio de 2017)].

Bravo, E. (2008). El español internacional. Cuadernos de Didáctica del Español/ le. Madrid: Arco Libros.

Cestero, A. M. (1999). Repertorio básico de signos no verbales del español. Madrid: Arco Libros.

Chinng, T. (2015). La bistoria de tu vida (título original: Stories of Your Life and Others). Traducción de Luis G. Prado. Madrid: Alamut.

Company, C. (2011). «Un diccionario a debate». Letras libres, 30 de abril [<http://www.letraslibres.com/mexico/un-diccionario-debate> (última consulta: 19 de junio de 2017)].

Fernández Montoro, D. (2014). «Implicaciones culturales del léxico». Tonos digital. Revista de estudios filológicos, 27 [<http://www.tonosdigital.com/ojs/ index.php/tonos/article/view/1133/701> (última consulta: 19 de junio de 2017)].

Forgas, E. (1996). «Lengua, sociedad y diccionario: la ideología». En: E. Forgas (coord.). Léxico y diccionarios. Tarragona. Departamento de Filologías Románicas: 71-90.

Forgas, E. (2001). «Diccionario e ideología: tres décadas de la sociedad española a través de los ejemplos lexicográficos». Espéculo: Revista de estudios literarios, $17 \quad[<\mathrm{http}: / /$ pendientedemigracion.ucm.es/info/especulo/ numero17/3decadas.html $>$ (última consulta: 19 de junio de 2017)].

Forgas, E. (2002). «Subjetividad y diccionarios. Las definiciones en los americanismos del DRAE». En: V. Sánchez Corrales (ed.). Actas del XIII Congreso Internacional de la Asociación Internacional de Filología de América Latina ALFAL, 18-23 de febrero. Universidad de Costa Rica. Ciudad Universitaria Rodrigo Facio: 699-706.

Forgas, E. (2006). «Diccionarios e ideología». Interlingüistica, 17: 2-16.

Galisson, R. (1991). De la langue à la culturele par les mots. Collection Didactique des langues étrangères. París: CLE Internacional.

García García, P. (2004). «Claves interculturales en el diseño de materiales didácticos para la enseñanza de español segunda lengua». Cultura e intercultura en la enseñanza del ELE [<http://www.ub.edu/filhis/culturele/pgarcia. html $>$ (última consulta: 19 de junio de 2017)].

Gaviño, V. (dir.) (2009). Diccionario de gestos españoles [<http://www.coloquial. es/es/diccionario-de-gestos-espanoles/> (última consulta: 19 de junio de 2017)]. 
Grebe, E.(1990)+«Concepción del tiempo en la cultura aymara: representaciones icónicas, cognición y simbolismo». Revista Chilena de Antropología, 9: 68-81.

Guevara, A. (2013). El español neutro. Realización hablada en audiovisuales, doblaje, web y telemarketing. Buenos Aires: Iberoamericana/Comunicación.

Gutiérrez Ordóñez, S. (1994). Estructuras comparativas. Cuadernos de lengua española. Madrid: Arco Libros.

Hanley, J. H. (1999). «Beyond the Tip of the Iceberg: Five Stages Toward Cultural Competence». Reaching Today's Youth, 3: 9-12 [<https*//www.ncjrs. gov/App/Publications/abstract.aspx?ID=177051> (última consulta: 19 de junio de 2017)].

Instituto Cervantes (2012). Las competencias clave del profesorado de lenguas segundas y extranjera [<http://cvc.cervantes.es/ensenanza/biblioteca_ele/ competencias/competencias_profesorado.pdf > (última consulta: 19 de junio de 2017)].

Kunn, T. (2006). La estructura de las revoluciones cientificas. Traducción de Carlos Solís. Madrid: Fondo de Cultura Económica de España.

Leal Riol, M. J. (2015). «Descubrir el agua tibia o inventar la pólvora. Variación diatópica de la fraseología española». Paremia, 24: 177-189 [<http://cvc. cervantes.es/lengua/paremia/pdf/024/016_leal.pdf> (última consulta: 19 de junio de 2017)].

López FACAL, J. (2011a). La presunta autoridad de los diccionarios. Madrid: CSIC. LópezFACAL,J.(2011b).EntrevistadeAliciaRiveraenElPaís,4defebrero[<http:// cultura.elpais.com/cultura/2011/03/04/actualidad/1299193207_850215. html> (última consulta: 19 de junio de 2017)].

López, M. y Morales, J. (2013). «La lexicultura. Una experiencia dentro y fuera del aula en el aprendizaje de ELE». Revista Nebrija de Lingüistica Aplicada a la Enseñanza de Lenguas, 13, 1/1 [<https;//www.nebrija.com/ revista-linguistica/files/.../articulo_53287f090b94c.pdf> (última consulta: 19 de junio de 2017)].

López Morales, H. (2006). La globalización del léxico hispánico. Madrid: Espasa.

Luan, Y. (2017). Propuesta para un diccionario cultural bilingüe (español-chinoespañol). Tesis doctoral leída en Tarragona, en la Universitat Rovira i Virgili, el 10 de marzo.

Luque Durán, J. de D. (2006). El diccionario intercultural e interlingüístico. Un paradigma para la comparación del español peninsular y el español de América [<http://studylib.es/doc/342106/el-diccionario-intercultural-einterling\%C3\%BC\%C3\%ADstico > (última consulta: 19 de junio de 2017)]. 
Luque Nadal, L. (2009). «Los culturemas: ¿unidades lingüísticas, ideológicas o culturales?». Language Design, 11: 93-120 [<http://elies.rediris.es/ Language_Design/LD11/LD11-05-Lucia.pdf> (última consulta: 19 de junio de 2017)].

LuQue NADAL, L. (2010). «Las referencias bíblicas en inglés y en español. Estudio culturológico-contrastivo». Odisea, 11: 269-283 [<http://repositorio.ual.es/ handle/10835/1148> (última consulta: 19 de junio de 2017)].

Maldonado, C. (1991). El discurso directo y el discurso indirecto. Madrid: Taurus. Maldonado, C. (dir.) (1993). Intermedio. Diccionario didáctico de español. Madrid: SM.

Maldonado, C. (1997). El fondo de las palabras. Madrid: SM.

Maldonado, C. (dir.) (2012a). Clave. Diccionario de uso del español actual, 9.a ed. Madrid: SM.

Maldonado, C. (2012b). «Los diccionarios en el mundo ELE: ayer, hoy y mañana (una reflexión desde la propia experiencia)». Revista Internacional de Lenguas Extranjeras, 1: 151-179.

Maldonado, C. (2013), «La entrada léxica en el discurso lexicográfico digital». Círculo de Lingüistica Aplicada a la Comunicación, 56: 26-52[<http:// revistas.ucm.es/index.php/CLAC/article/view/43866/41467> (última consulta: 19 de junio de 2017)].

Millás, J. J. (2009). «Las palabras de nuestra vida». La opinión de Tenerife, 24 de febrero $[<$ http://www.fundeu.es/noticia/las-palabras-de-nuestravida-5064/> (última consulta: 19 de junio de 2017)].

Molero, A. (2008). El español de España y el español de América. Vocabulario comparado. Madrid: SM.

Moreno, F. (2000). Qué español enseñar. Cuadernos de Didáctica del Español/ le. Madrid: Arco Libros.

Pascual, J. A. y Olaguíbel, M.C. (1991). «Ideología y diccionario». En I. Ahumada Lara (ed.). Diccionarios españoles: contenido y aplicaciones. Lecciones del I Seminario de Lexicografía Hispánica. Jaén. El EstudianteFacultad de Humanidades: 73-89.

Petrescu, O. (2008). «La traducción de los culturemas (Discusión al margen de la traducción de una novela de Guillermo Arriaga). Valenciana. Estudios de Filosofía y Letras, 11: 139-172 [<http://www.revistavalenciana.ugto. $\mathrm{mx} /$ index.php/valenciana/article/view/218> (última consulta: 19 de junio de 2017)].

Prado Aragonés, J. (2005). "Tópicos culturales en los diccionarios de enseñanza de ElE». En: M. A. Castillo Carballo, O. Cruz Moya, J. M. 
García Platero y J. P. Mora Gutiérrez (coords.). Las gramáticas y los diccionarios en la enseñanza del español como segunda lengua: deseo y realidad. Asociación para la Enseñanza del Español como Lengua Extranjera (XV Congreso Internacional de la ASELE, Sevilla, 2004). Sevilla. Universidad de Sevilla: 705-709.

Rey, A. (1987). «Le dictionnaire culturel». En: A. Kucera, A. Rey, H. E. Wiegand y L. Zgusta (eds.). Lexicographica. International Annual for Lexicography, vol. 3. Tubinga. Max Niemeyer Verlag: 3-50.

Satorre Grau, J. (2015). «La comparación elativa en la historiografía lingüística española». Revista Iberoamericana de Lingüistica, 10: 93-122 [<http:// roderic. uv.es / bitstream/handle/10550/49246/108587.pdf?sequence $=1 \&$ isAllo. wed $=y>$ (última consulta: 19 de junio de 2017)].

Weaver, G. (1998). «Understanding and Coping with Cross-cultural Adjustment Stress». En: G. Weaver (ed.). Culture, Communication and Conflict: Readings in Intercultural Relations. Londres: Simon \& Schuster Publishing [ $<$ http $/ /$ home.snu.edu/ HCULBERT/iceberg.htm> (última consulta: 19 de junio de 2017)]. 